\title{
Pharmacologically induced absence seizures versus kindling in Wistar rats
}

\author{
Nihan Carcak, ${ }^{1}$ (i) Melike Sahiner, ${ }^{2}$ (D) Ozlem Akman, ${ }^{3}$ (I) Medine Gulcebi Idrizoglu, ${ }^{4}$ \\ (1) Miguel A. Cortez, ${ }^{5}$ () 0. Carter Snead, ${ }^{5}$ (i) Esat Eskazan, ${ }^{6}$ (i) Filiz Onat $^{4}$ \\ ${ }^{1}$ Department of Pharmacology, Istanbul University Faculty of Pharmacy, Istanbul, Turkey \\ ${ }^{2}$ Department of Physiology, Acibadem Mehmet Ali Aydinlar University Faculty of Medicine, Istanbul, Turkey \\ ${ }^{3}$ Department of Physiology, Istanbul Bilim University Faculty of Medicine, Istanbul, Turkey \\ ${ }^{4}$ Department of Medical Pharmacology, Marmara University Faculty of Medicine, Istanbul, Turkey \\ ${ }^{5}$ Department of Pediatric Neurology, Toronto University Faculty of Medicine, Toronto, Canada \\ ${ }^{6}$ Deaprtment of Medical Pharmacology, Istanbul University-Cerrahpasa, Cerrahpasa Faculty of Medicine, Istanbul, Turkey
}

\begin{abstract}
OBJECTIVE: This study aimed to investigate the effects of $\gamma$-butyrolactone (GBL), a prodrug of gamma-Hydroxybutyric acid -induced absence seizures on the development of kindling in Wistar rats.

METHODS: Three groups of adult male Wistar rats under anesthesia were implanted with bilateral cortical recording electrodes for the GBL group (GBL) and/or bipolar stimulation electrodes into the right basolateral amygdala for the Kindling group (KI) alone and Kindling plus GBL group (GBL+KI). Rats in the $\mathrm{KI}$ and GBL+KI groups were stimulated twice daily at the afterdischarge threshold until they reached Racine's stage 5 seizure state. The animals in the GBL + group had an i.p injection of GBL 20 minutes before each electrical stimulation, and the effects of GBL-induced seizures on the development of kindling were investigated. The animals in the GBL group were injected GBL twice daily i.p. for 15 days without receiving any electrical stimulation.
\end{abstract}

RESULTS: The KI animals reached stage 5 seizure stage at $12^{\text {th }}$ stimulations, whereas the GBL+KI rats reached at $27^{\text {th }}$ stimulations. The mean numbers of stimulations needed for the development of the first stage 3,4 , or 5 generalized seizures were significantly higher in the GBL+KI group than the KI group.

CONCLUSION: The resistance to amygdala kindling in the GBL model can be modulated by the absence seizure mechanism alone, without the intervention of an abnormal genetic background.

Keywords: Amygdala; gamma-butyrolactone; experimental limbic epilepsy; genetic absence epilepsy; kindling.

Cite this article as: Carcak N, Sahiner M, Akman O, Gulcebi Idrizoglu M, Cortez MA, Snead OC, et al. Pharmacologically induced absence seizures versus kindling in Wistar rats. North Clin Istanb 2020;7(1):25-34.

$\mathrm{K}$ indling is the classical model for temporal lobe epilepsy with a repeated focal application of the low-intensity electrical current to a particular forebrain structure that predictably triggers the initial partial seizure [1-4]. The resistance to kindling induced secondary generalization from limbic seizures is a phe- nomenon observed in genetically determined genetic rat models of absence epilepsy; the Genetic Absence Epilepsy Rats from Strasbourg (GAERS) and Wistar Albino Glaxo rats from Rijswijk (WAG/Rij) [5, $6]$. In these models, the presence of generalized spikeand-wave discharges (SWDs) is clearly associated

Received: March 13, 2018 Accepted: January 03, 2019 Online: March 08, 2019

Correspondence: Dr. Filiz ONAT. Marmara Universitesi Tip Fakultesi, Tibbi Farmakoloji Anabilim Dalı, Istanbul, Turkey.

Tel: +90 5323712131 e-mail: fonat@marmara.edu.tr

(c) Copyright 2020 by Istanbul Provincial Directorate of Health - Available online at www.northclinist.com 
with resistance to experimental induced temporal lobe seizures $[7,8]$. The resistance to kindling in genetic absence epilepsy models is related to the development and also to the total duration of the SWDs, which are the electroencephalogram (EEG) hallmark of the unique neural circuitry of typical absence epilepsy [7, 9-12]. To date, data concerning the resistance to temporal lobe epilepsy conveyed by SWDs have been generated only from genetic absence epilepsy rat models. This raises a question as to whether the resistance to kindling depends on the genetic background of these specific models or relate to the neural mechanisms of absence epilepsy itself. Therefore, we used the genetically normal Wistar strain of rats and a pharmacological model that is reproducible and predictable for the EEG and behavioral characteristics of generalized typical absence seizures in humans, namely the gamma-hydroxybutyrate (GHB) model $[13,14]$. GBL model is based on the systemic administration of gamma-butyrolactone (GBL), the prodrug of GHB, known to produce exactly the same electrographic and behavioral effects of experimental typical absence seizures comparable to human absence epilepsy $[15,16,17]$. Further, GBL is used in lieu of GHB to induce this model of absence seizures because of the consistency, predictable dose-response and, rapidity of the onset of the action of GBL [17-19]. The systemic administration of GBL produces absence seizures through the potentiation of the GHB-related neuromodulation and/or interaction with GABAergic inhibitory and excitatory neurotransmission within cortico-thalamo-cortical circuitry [18].

The objective of our kindling study in genetically normal Wistar rats undergoing GBL-induced absence seizures was to determine whether the resistance to the development of kindling observed in experimental absence epilepsy, can be independent of the genetic background.

\section{MATERIALS AND METHODS}

Animals

Adult (6-8 months-old) Wistar male rats weighing 270-300 g were used for all experiments. Animals were housed in a temperature controlled room $\left(20 \pm 3{ }^{\circ} \mathrm{C}\right)$ with a 12-h light-dark cycle in groups of four per cage and separated individually after the surgery with free access to commercial rat pellets and tap water. The experimental protocol in this study was approved by the local ethical committee of animal research.
The animals were randomly organized in three groups. Group 1 was treated with GBL only (GBL, $n=$ 6); Group 2 was treated with GBL and received kindling stimulation $(\mathrm{GBL}+\mathrm{KI}, \mathrm{n}=6)$. Finally, Group 3 received kindling stimulation only, without GBL treatment (KI, $\mathrm{n}=7$ ).

\section{Surgery}

Animals were anaesthetized with ketamine $(100 \mathrm{mg} /$ $\mathrm{kg}$, intraperitoneally (i.p.)) and xylazine $(10 \mathrm{mg} / \mathrm{kg}$, i.p.). Each animal of the GBL, GBL+KI and KI groups was placed in a stereotaxic instrument (Stoelting Model 51600, Stoelting Co., Illinois, USA) with the skull surface flat and bregma 0.0 . The scalp was longitudinally incised for the implantation of stainless steel screws, and screw electrodes were placed bilaterally in the skull over frontal and parietal cortices for EEG recordings. Plastic's One bipolar stimulating and recording electrodes (Roanoke, VA, USA, MS303/1) were implanted into the right basolateral amygdala (BLA) of the GBL+KI and KI groups. The stereotaxic coordinates [20] for the localization of BLA $(2.6 \mathrm{~mm}$ posterior, $4.8 \mathrm{~mm}$ lateral from bregma and $8.5 \mathrm{~mm}$ ventral from the skull). All of the electrodes were fixed to the skull with dental acrylic and linked by insulated wires to a connector for the EEG recordings. The animals were allowed to recover from surgery for one week before any experimental protocols were started.

\section{Experimental Protocol}

On the first day of the experiment, all animals were placed in Plexiglas recording cages. After an adaptation period, a baseline EEG was recorded for $20 \mathrm{~min}$, as indicated in the experimental design (Fig. 1). Electrical activities of the cortex and/or BLA were amplified (BioAmp ML 136) and recorded with a PowerLab 8S System running Chart v.5, (ADI Instruments, Oxfordshire, U.K.) before and after each GBL injection and/ or each electrical kindling stimulation at their afterdischarge threshold. GBL was purchased from Sigma Aldrich (St Louis, U.S.A) and prepared in saline for the i.p. injections. For the GBL and GBL+KI groups, a dose of $100 \mathrm{mg} / \mathrm{kg}$ of GBL was chosen based on the previous literature $[18,19]$. GBL is readily hydrolyzed in vivo to its active congener, GHB [21].

\section{The GBL Group}

The rats in the GBL group were administered 30 i.p. in- 


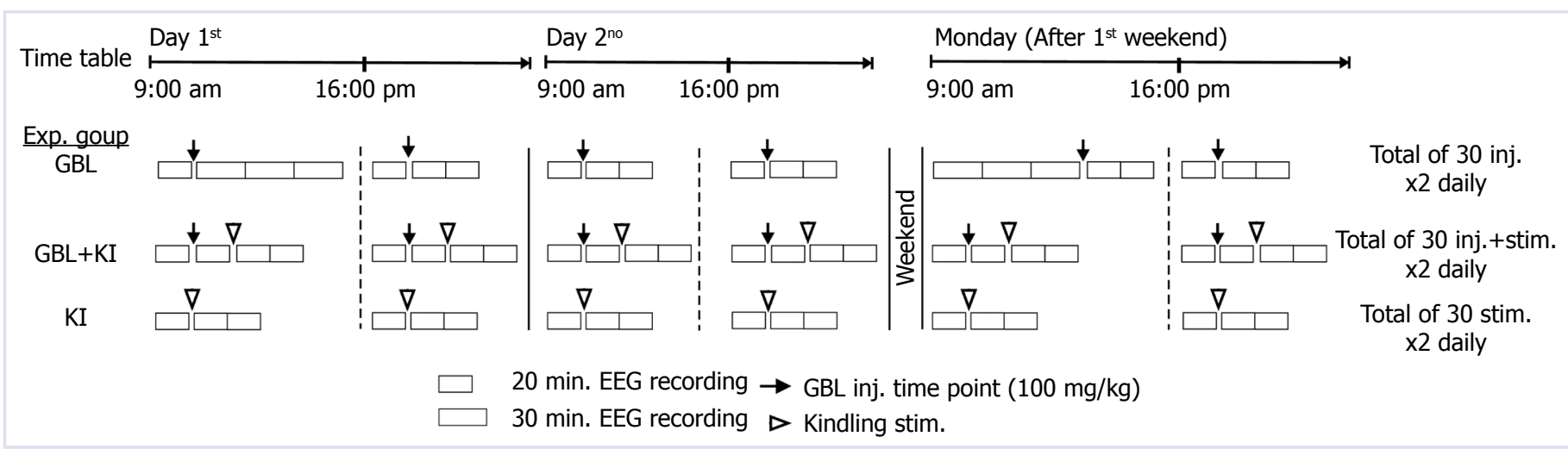

FIGURE 1. Design of the Gamma-butyrolactone (GBL), Kindling (KI) and GBL+KI experiments. Experimental protocol of GBL injections and/or kindling stimulations along with the EEG recording periods are seen for the three experimental groups: GBL, GBL+KI and $\mathrm{KI}$ alone. EEG recording periods are presented by rectangular clear boxes either of 20 or 30 min duration. Solid black arrows indicate the time of GBL injections and the clear arrows show the kindling stimulation time points. A total of $30 \mathrm{GBL}$ i.p injections were performed in all groups, over a period of three weeks.

jections of GBL twice daily from day Monday to Friday at the same time as the GBL+KI and KI groups, but did not receive electrical stimulation over the three weeks pe$\operatorname{riod}($ Fig. 1). The EEG was recorded continuously $90 \mathrm{~min}$ after the first GBL injection to determine the duration of the acute GBL effect. Then for the rest of the week, EEG was recorded $20 \mathrm{~min}$ before and $40 \mathrm{~min}$ after GBL injections to evaluate GBL-induced discharges with chronic administration of GBL throughout the three weeks. To monitor spontaneous SWDs, the baseline EEG on the subsequent Monday mornings after the first, second and third weekends were recorded for $90 \mathrm{~min}$.

\section{The GBL+KI and KI Groups}

To determine the afterdischarge threshold of the $\mathrm{GBL}+\mathrm{KI}$ or KI groups, the right BLA was stimulated with an initial stimulus of $50 \mu \mathrm{A}$ (monophasic, squarewave pulses of $80 \mathrm{~Hz}$, each $1 \mathrm{~ms}$ in duration, for a total duration of $2 \mathrm{~s}$ ). This was continued with $50 \mu \mathrm{A}$ increments until an initial afterdischarge in EEG was obtained for $\mathrm{KI}$ or $\mathrm{GBL}+\mathrm{KI}$ groups, before the beginning of the experimental protocol. The minimal duration of the afterdischarge activity was accepted as a spike discharge lasting $\geq 2 \mathrm{~s}$ immediately after the stimulation [1]. The animals in the GBL+KI and KI groups were stimulated at the afterdischarge threshold current, twice daily from Monday to Friday (Fig. 1). The GBL+KI group received kindling stimulation 20 min after the i.p. GBL injection. Seizure stages observed after each stimulation were classified for both groups using Racine's standard five-stage scale: stage 1 , facial movements; stage 2 , rhythmic head movements, head nodding; stage 3, unilateral forelimb clonus; stage 4, bilateral forelimb clonus and rearing; stage 5, falling and clonic convulsion [22]. As indicated, the animals of GBL+KI or KI groups were stimulated until they reached a stage 5 seizure state. If the animal had at least three consecutive stage 5 seizures, it was accepted as the endpoint of the experiment for that rat. The EEG of the GBL+KI group was recorded continuously for $20 \mathrm{~min}$ before and after the GBL administration and subsequently for $40 \mathrm{~min}$ after the kindling stimulation to analyze after discharge and SWD durations. The EEG of the KI group was monitored continuously for $20 \mathrm{~min}$ before and $40 \mathrm{~min}$ after the kindling stimulation to analyze after discharge durations (Fig. 1).

Evaluation of GBL-induced Discharges after Acute and Chronic Administration

A GBL-induced discharge was identified visually as such if its duration was $\geq 1 \mathrm{~s}$ with a complex of spike-andwave $(5-6 \mathrm{~Hz})$ and the amplitude at least three times the background amplitude of the EEG was the inclusion criteria (Fig. 2A). The GBL-induced discharges were referred to as SWDs captured on the EEG. The cumulative and mean duration of SWDs in the GBL group and only the cumulative duration of SWDs in the GBL+KI group were evaluated.

The spectral characteristics of SWDs in the GBL group were analyzed by computing power spectra using the Fast Fourier Transform (FFT) (The MathWorks MATLAB 7.6, USA). The power spectra of the mid- 


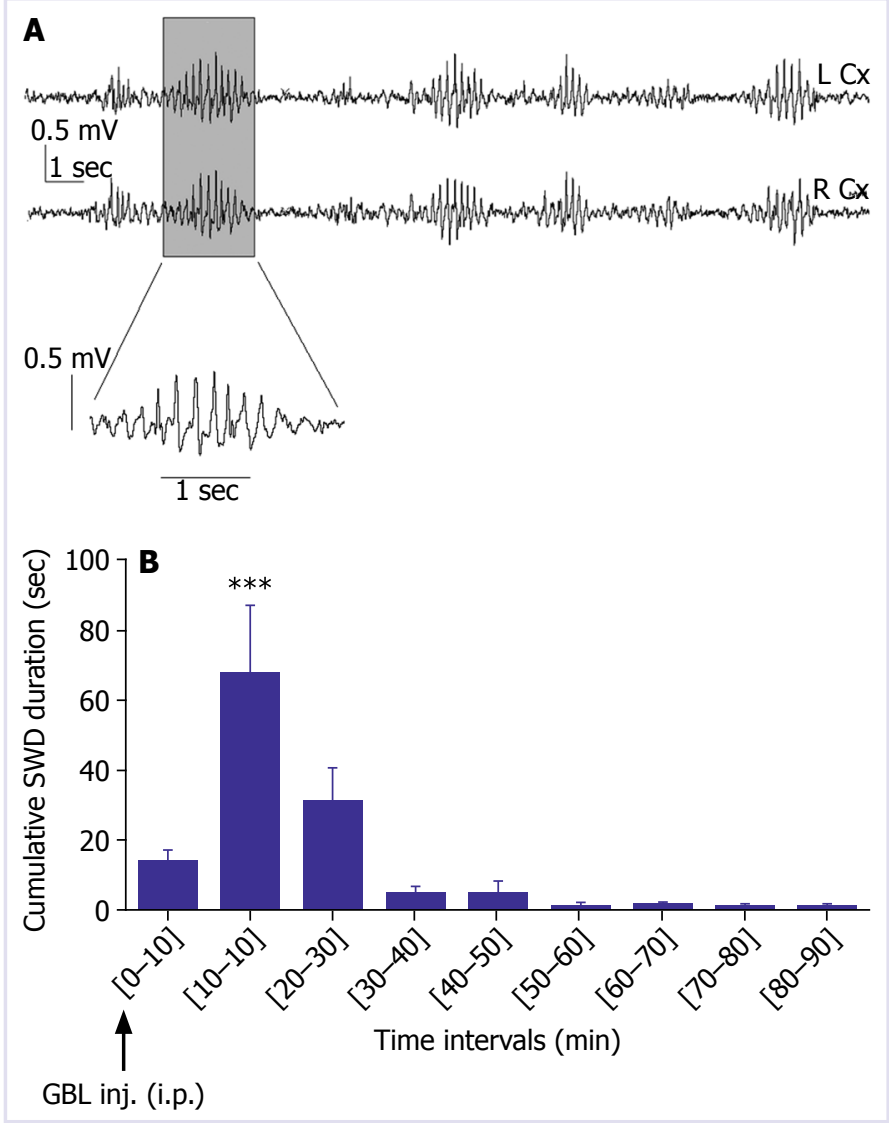

FIGURE2. The representative electrographic pattern of SWDs from the left $(L)$ and right $(R)$ cortical $(C x)$ regions, induced by the $1^{\text {st }}$ injection of GBL in Wistar rats. The magnification of the EEG signal from the gray rectangle shows a burst of SWD at the frequency of $5-6 \mathrm{~Hz}$ at the visual inspection (A) and the cumulative duration of SWDs after the first GBL injections over a 90 min period (B). ${ }^{* *} p<0.01$, revealed by one-way ANOVA followed by the post hoc Bonferroni test. Voltage/time scale: $0.5 \mathrm{mV} / 1 \mathrm{sec}$.

dle $1 \mathrm{~s}$ segments of the SWDs were computed for each group. The average power-spectra of randomly selected 15 SWDs were computed for each animal. The spectral changes of SWDs after the $1^{\text {st }}$ and $20^{\text {th }}$ injection of GBL were displayed in the form of spectrograms based on the power spectra. Further, the relative strength of the first harmonic was calculated by dividing the power at the first harmonic frequency by the power at the fundamental frequency.

Evaluation of the Kindling-induced Stages and Afterdischarges in the EEG

Seizure stages (kindling rate), and the total duration of the afterdischarges were evaluated immediately after the
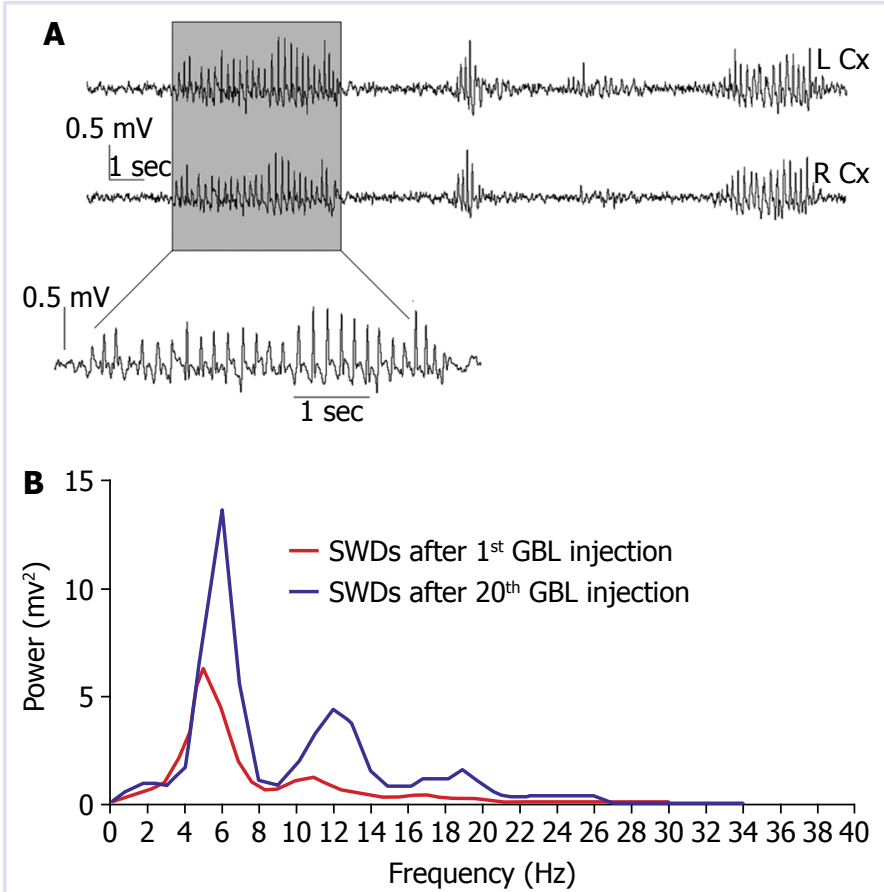

FIGURE 3. The representative electrographic pattern of SWDs induced after the $20^{\text {th }}$ injection of GBL in Wistar rats. The magnification of the EEG signal from the gray rectangle shows a $5 \mathrm{sec}$ burst of SWD at the frequency of $6 \mathrm{~Hz}$ at the visual inspection. Voltage/time scale: $0.5 \mathrm{mV} / 1 \mathrm{sec}$. Abbreviations: Left $(L)$ and right $(R)$ cortex $(C x)(A)$. The power spectra of the GBL-induced SWDs after $1^{\text {st }}$ and $20^{\text {th }}$ injections, with a dotted line for the first GBL injection compared to that after the $20^{\text {th }} \mathrm{GBL}$ injection represented with the solid line. There is a primary peak at the frequency of $5.16 \pm 0.16 \mathrm{~Hz}$ followed by a secondary peak with a small power at the first harmonic frequency of $10.67 \pm 0.21 \mathrm{~Hz}$ (B). The frequency and the power at the fundamental frequency of SWDs were increased significantly after the repeated injections of GBL $(p<0.05)$.

electrical stimulation in the GBL+KI and KI groups. The mean number of stimulations needed to reach the first stage 2, 3, 4 or 5 was also evaluated in the GBL+KI and KI groups.

\section{Histological Verification}

After the KI and GBL+K experiments, the animals were decapitated and the brains were put into a formalin/ sucrose mixture. The brains were cut as $40 \mu \mathrm{m}$ frozen sections in a cryostat and stained with thionine to determine the electrode placement. Only the animals with a correct electrode placement in the BLA were included in this study. 


\section{Statistical Analysis}

Data were expressed as mean \pm SEM and statistically evaluated by analysis of variance of repeated measures (ANOVA). A one-way ANOVA followed by the post hoc Bonferroni test was used to analyze the cumulative duration of SWDs after the first GBL injection, as well as the cumulative and mean duration of spontaneous SWDs after the first, second and third weekends in the GBL group. Paired t-test was used to analyze the differences between frequencies and the power of the fundamental frequency of SWDs and the relative strength of the first harmonic of SWDs after $1^{\text {st }}$ vs $20^{\text {th }}$ injections of GBL in the GBL group.

A two-way ANOVA followed by the post-hoc Bonferroni test was used to analyze the kindling rate, afterdischarge duration and the mean number of stimulations needed to reach the first stage $2,3,4$, or 5 seizures of the GBL+KI and KI groups. A one-way ANOVA followed by the post- hoc Bonferroni was used to compare the cumulative duration of SWDs in GBL and GBL+KI groups. The level of statistical significance was considered to be $\mathrm{p}<0.05$.

\section{RESULTS}

The baseline EEG recordings of all Wistar rats showed no abnormal discharges.

\section{The Effects of Acute and Chronic GBL Administration (GBL Group)}

The administration of GBL caused a rapid onset of bilaterally synchronous discharges in the cortical EEG accompanied by immobility, vacant-staring, and vibrissal twitching. After the first injections, these discharges appeared as a series of SWD complexes with a mean duration of $1.3 \pm 0.2 \mathrm{sec}$ with sudden initiation and termination (Fig. 2A). The SWDs are appeared $4.8 \pm 0.7$ min after the first injection of GBL, reached maximum numbers and durations within $20 \mathrm{~min}$ and disappeared by $90 \mathrm{~min}$ (Fig. 2B). These complexes became regular, waxing and waning rhythmic SWDs with the repeated chronic administration (Fig. 3A). The mean duration of SWDs after the $20^{\text {th }}$ injection was $3.0 \pm 0.8 \mathrm{sec}$ that was significantly longer than those observed in the initial administrations $(p<0.01)$. The latency for the onset of the first SWD complex was found to be delayed by repeated injections of GBL and reached to $10.5 \pm 2.7 \mathrm{~min}$ after the $30^{\text {th }}$ injection.

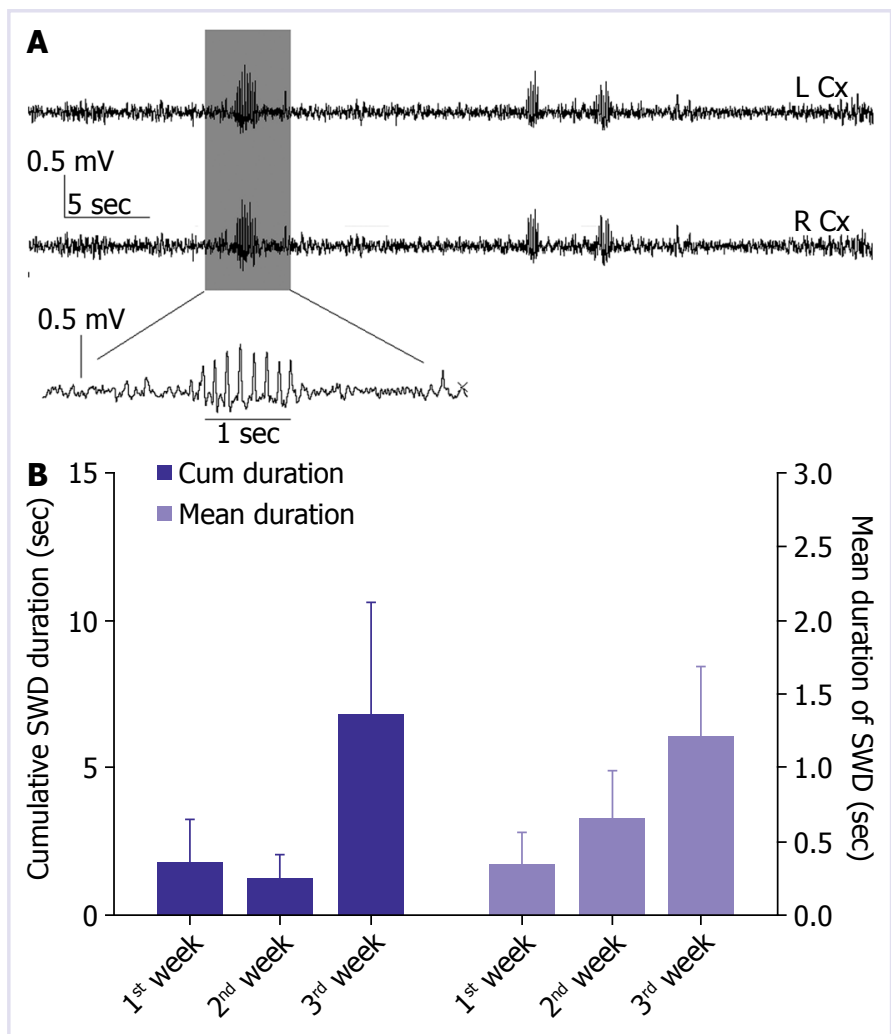

FIGURE 4. The representative pattern of spontaneous bilateral synchronous SWDs in the baseline EEG on the monday morning session after the $3^{\text {rd }} \mathrm{GBL}$-free weekend period with a slow speed in order to demonstrate the subsequent SWD complexes together. The magnification of the 5 sec EEG signal from the gray rectangle shows a burst of SWD at the frequency of $6.8 \mathrm{~Hz}$. Abbreviations: Left $(\mathrm{L})$ and right (R) cortex (Cx) (A). The cumulative and mean duration of spontaneous SWDs throughout the 3-weeks experimental period, during the chronic GBL systemic administration (B). The statistical analysis revealed a significant increase in cumulative duration of spontaneous SWDs after the $3^{\text {rd }}$ weekend $(p<0.05)$, one-way ANOVA. Voltage/time scale: $0.5 \mathrm{mV} / 1 \mathrm{sec}$.

The power spectra of the SWD complexes after the $1^{\text {st }}$ injection (acute administration) consisted of a peak at the fundamental frequency of $5.2 \pm 0.2 \mathrm{~Hz}$, and a secondary peak with a small power at the first harmonic frequency of $10.7 \pm 0.2 \mathrm{~Hz}$ (Fig. 3B). After the $20^{\text {th }}$ injection (chronic administration), the fundamental frequency of the SWD complex increased significantly to $6.0 \pm 0.3 \mathrm{~Hz}$ $(\mathrm{p}<0.05)$ and in addition to a more pronounced peak at the first harmonic frequency of $11.9 \pm 0.5$, a third clearly visible peak appeared at the second harmonic frequency of $18.0 \pm 0.6 \mathrm{~Hz}$ (Fig. 3B). Additionally, the power at the 
fundamental frequency increased significantly after the repeated injections of GBL $(p<0.05)$ during the chronic administration. Because the peak at the first harmonic was observed in both conditions, the relative strength of the first harmonic was calculated by dividing the power at the first harmonic frequency by the power at the fundamental frequency, and this ratio was compared between both conditions. Statistical analysis revealed that this ratio was increased significantly after $20^{\text {th }}$ injection $\left(0.2 \pm 0.4\right.$ after the $1^{\text {st }}$ injection vs $0.4 \pm 0.1$ after the $20^{\text {th }}$ injection; $\mathrm{p}<0.05)$.

As shown in Figure 4A, by repeated GBL injections, animals displayed spontaneous bilateral synchronous SWDs in the baseline EEG on the Monday morning session after the GBL-free weekend period (60 h after the Friday afternoon injection). The cumulative and mean duration of spontaneous SWDs were increased throughout the 3-weeks experimental period in the chronic administration. The statistical analysis revealed a significant increase in the cumulative duration of spontaneous SWDs after the third weekend (Fig. 4B).

\section{The Development of Kindling in the GBL+KI and KI Groups}

All rats in the KI and GBL+KI groups reached stage 5. There was a difference, however, in the number of stage 5 triggering stimulations: the KI group revealed stage 5 seizures by 12 stimulations, whereas not all animals of GBL+KI showed stage 5 seizures until the $27^{\text {th }}$ stimulation (Fig. 5A). This seems to indicate that kindling was less effective in the GBL+KI group compared to the KI group. Furthermore, there was a marked increase from stage 2 to stage $3-4$ in the GBL+KI group after the $15^{\text {th }}$ to $18^{\text {th }}$ stimulation (Fig. $5 \mathrm{~A}$ ). The mean number of stimulations for the occurrence of the first seizures of stage 3, 4 or 5 were significantly higher in the GBL+KI animals than in the KI group $(p<0.001)$, whereas the number of stimulations needed to produce the first stage 2 seizure was similar in both KI and GBL+KI groups (Fig. 5B). As indicated in Figure 5C, the afterdischarge durations of the GBL+KI and KI groups showed no significant difference. The mean afterdischarge threshold was $185.7 \pm 28.3$ $\mu \mathrm{A}$ in the $\mathrm{KI}$ group and $205.6 \pm 29.4 \mu \mathrm{A}$ in the GBL+KI group, therefore, it was not statistically significant.

The Effects of Kindling on GBL-induced Discharges in the GBL+KI Group

The GBL-induced SWD complexes appeared 3.9 \pm 1.1
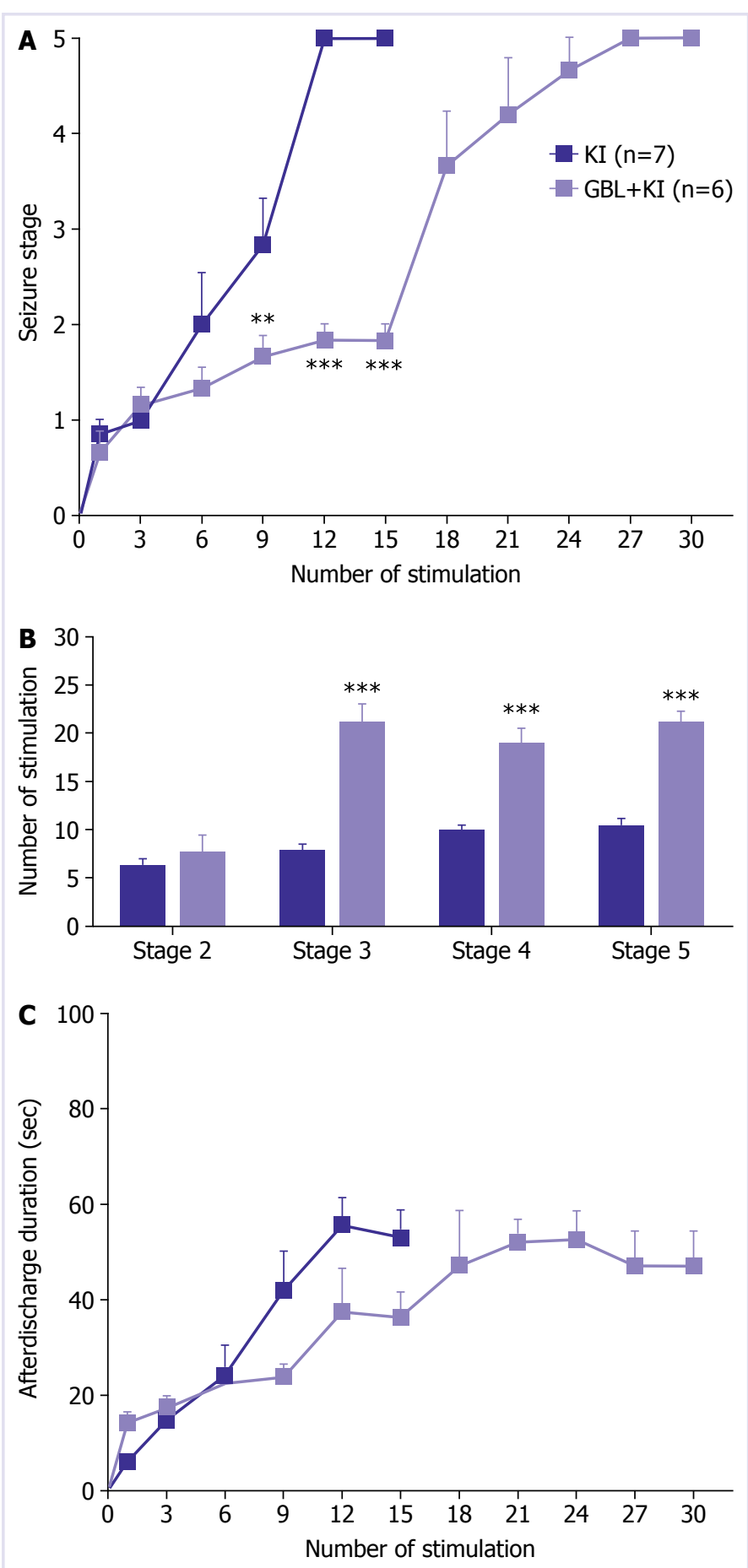

FIGURE 5. The development of kindling in the Gamma-butyrolactone (GBL)+ Kindling (KI) and KI groups. Seizure stage reached $(\mathbf{A})$, the mean number of stimulations for the development of first stage 3, 4, and 5 seizure stages (B) and the duration of afterdischarge (ADD) in the ipsilateral amygdala of $\mathrm{KI}$ and $\mathrm{GBL}+\mathrm{KI}$ groups (C). Data expressed as mean \pm S.E.M. ${ }^{* *} p<0.01, * * * p<0.001$, significant differences between the KI and GBL+KI groups revealed by twoway ANOVA followed by post-hoc Bonferroni test. 


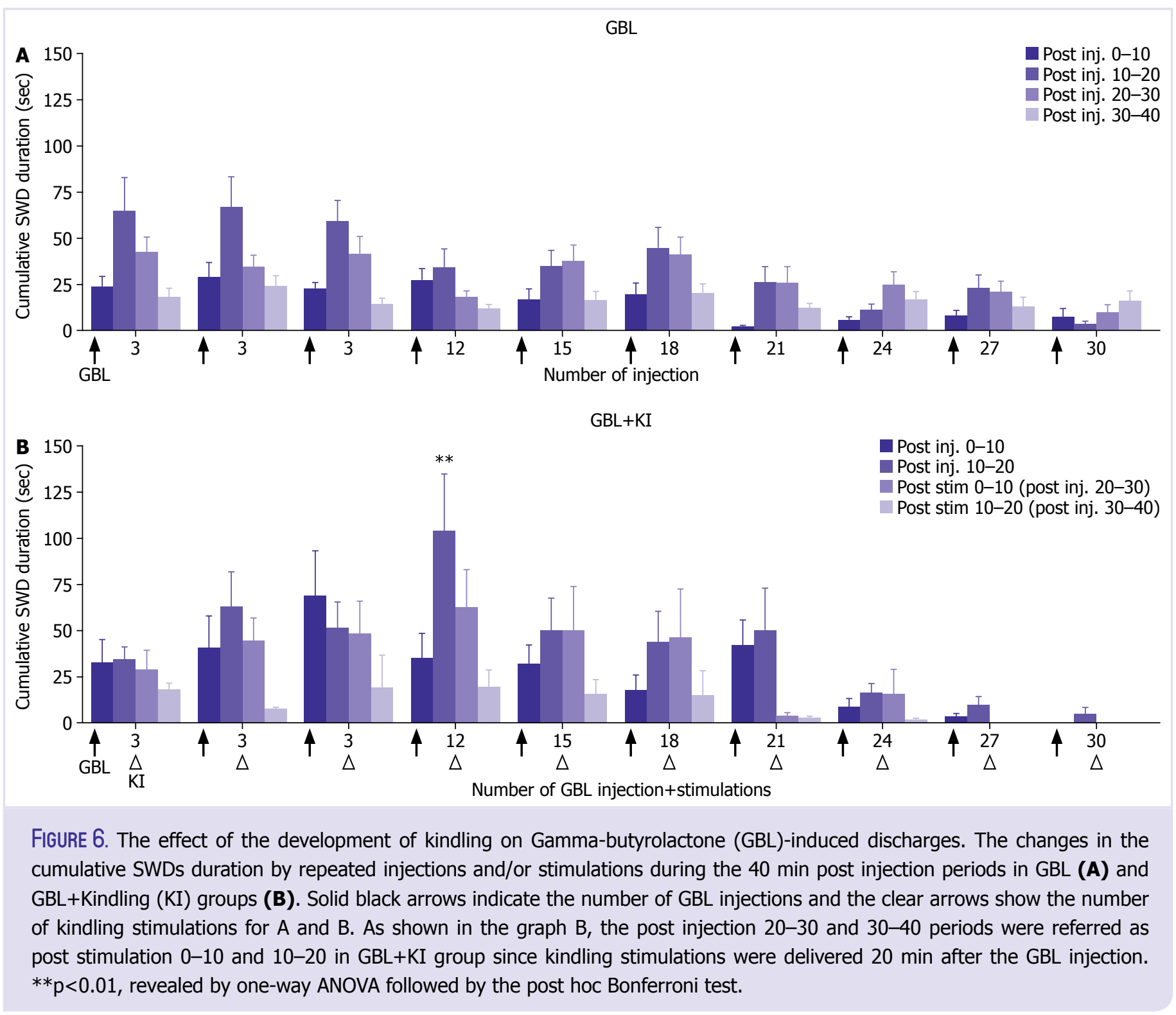

min after the first injection of GBL (acute administration) in the EEG of the GBL+KI group, which is similar to that observed in the GBL group after the first injection. The latency to onset of the first SWD complex was delayed by repeated injections of GBL and reached to $14.9 \pm 3.7 \mathrm{~min}$ after the $30^{\text {th }}$ consecutive injection.

The GBL+KI group showed the longer cumulative duration of SWDs at the $10-20 \mathrm{~min}$ period of the $12^{\text {th }}$ post-injection relative to the same time period of the GBL group. Thus, it was considered statistically significant ( $<<0.01$; Fig. 6A, B). In the GBL+KI group, the GBL-induced discharges disappeared in both post-injection and post-stimulation periods when they became kindled at the $27^{\text {th }}$ and/or $30^{\text {th }}$ stimulations.

\section{DISCUSSION}

The present study showed that 1) in non-epileptic animals that received chronic administration of GBL, the GBL-induced discharges consisting of spike/spike-andwave complexes became a more typical or mature form of SWD over the repeated i.p. injections of $100 \mathrm{mg} / \mathrm{kg}$ in the GBL group; 2) in the GBL+KI group, there was an apparent delay in the development of the kindling course and the changes in the SWD duration occur with an inverse relation to the kindling stages.

This study demonstrated a delay in the development of kindling when electrical stimulation was preceded by the i.p. administration of $100 \mathrm{mg} / \mathrm{kg}$ of GBL and also 
a change in the duration of SWDs, which may account for a mutual cross interaction between absence epilepsy and temporal lobe epilepsy. This interaction seems to be independent of the genetic background. This mutual cross interaction between absence epilepsy and temporal lobe epilepsy was recently reported in experimental conditions $[5,6]$. In these studies, rats with genetically determined absence epilepsy displayed either full or partial resistance, depending on the genetic background, to the amygdaloid, hippocampal, or perirhinal cortical kindling [7-12]. In accordance with our findings, electrical co-stimulation of the thalamic reticular nucleus during the rapid hippocampal kindling procedure suppresses the development of generalized limbic seizures in the adult control Wistar rats [23]. A similar protective interaction was also described in a genetic mouse model of absence epilepsy [24]. Furthermore, such seizure type interaction was observed with the development of focal limbic epilepsy in GAERS and largely impaired the expression of absence seizures. Following the application of lithium-pilocarpine, the spontaneous absence seizures were delayed in GAERS compared with Wistar rats [25]. A better understanding of the mutual cross interaction between these two types of epilepsy raises the question as to whether the partial or full resistance to the electrical kindling, when animals are stimulated at their afterdischarge, is attributed to the genetic absence epilepsy rats or the absence seizures in general. Our findings here demonstrate that the resistance to the kindling in the GHB model is influenced by the mechanism of the absence of epilepsy itself without the intervention of an abnormal genetic background. Thus, it is circuitry-dependent. This is apparently the case, at least to some degree, in the development of kindling by electrical stimulation of limbic structures in rats with genetic absence epilepsy or chemically-induced absence seizures.

In a previous study, electrical stimulation of the neocortex of Spraque-Dawley rats at $400 \mu \mathrm{A}$ resulted in generalized kindled cortical seizures [26]. When the effects of several cataleptic and depressant anesthetics were evaluated based on the behavioural and afterdischarge duration responses of kindled cortical seizures, a dose of $100 \mathrm{mg} / \mathrm{kg}$ of GBL affected neither the afterdischarge duration nor the behavioural seizure activity [26]. A further study of the same group demonstrated that the doses of 200 or $450 \mathrm{mg} / \mathrm{kg}$ of GBL produced a delay on the kindling process when the Spraque-Dawley rats were stimulated at $400 \mu \mathrm{A}$ [27]. However, the findings in these studies do not necessarily interfere with our re- sults due to the methodological differences, including the higher doses of GBL than the dose in the present work $(100 \mathrm{mg} / \mathrm{kg})$ and the stimulation current used $(400 \mu \mathrm{A}$ vs $205.6 \pm 29.4 \mu \mathrm{A}$ in the present work).

It is also of interest to investigate the cellular and/ or molecular mechanisms underlying the interaction of chemical absence epilepsy with kindling. GBL is converted rapidly and irreversibly to $G H B$ after parenteral administration and is biologically inactive $[18,19]$. GHB has multiple mechanisms of action in the brain, including the activation of both the $\gamma$-aminobutyric acid type $B$ (GABAB) receptor and a separate GHB-specific receptor, as well as the suppression of the glutamate receptor subunit B (GluR2) $[16,28,29]$. The findings in GluR2 null mutant mice highlight the involvement of the GluR2 subunit in the initiation and maintenance of absence seizures induced by GBL [29]. Further, an analysis of the mouse thalamic proteome using fluorescence 2D difference gel electrophoresis combined with mass spectrometry showed reversible changes in the expression of particular proteins corresponding to the appearance of SWDs $10 \mathrm{~min}$ after the i.p. administration of $50 \mathrm{mg} / \mathrm{kg}$ GBL [30]. Indeed, many further studies addressing the neural correlates of this mutual cross interaction based on GBL-related changes in the brain will provide evidence for the mechanisms underlying the issue. For instance, it is conceivable that GBL mediated mechanisms of absence seizures might have ameliorated the reported changes in neurogenesis in our GBL+KI group [31].

We should note that the present study reproduced the acute and characterized the chronic effects of the systemic administration of GBL. The EEG and behavioral characteristics of GBL-induced discharges with a dose of 100 $\mathrm{mg} / \mathrm{kg}$ are in line with the previous observations $[18,32$, 33]. The initial electrographic change in the baseline EEG recorded from the right and left frontoparietal cortices was a brief burst of spikes, which thereafter quickly progressed to the typical SWDs of absence seizures, as reported previously [18]. These GBL-induced bilateral synchronous discharges in the acute administration show irregularity in the rhythmicity, duration, and amplitude. These electrographic discharges after the first injections were similar to the immature SWD paroxysms observed in postnatal 30 days old GAERS [7]. With repeated chronic administration of GBL, the SWD complexes appeared to mature with an increase in the power at the fundamental frequency and similar to that in adult GAERS or WAG/Rij rats [34]. As shown in previous studies carried out on genetic animal models of absence epilepsy, the typical SWD 
pattern is characterized by the presence of strong peaks at the harmonics of the fundamental SWD frequency in the power spectrum $[34,35]$. The ratio of the power of the first harmonic to the power of the fundamental frequency reflects higher weights of the faster components in a single SWD cycle and increases with the SWD maturation $[7,34]$. Therefore, the significantly higher frequency of the SWDs and the significantly higher power ratio of the spectral peak at the first harmonic frequency show that the GBL-induced SWD pattern became more typical and mature after the $20^{\text {th }}$ injection of GBL.

It is accepted that the major disadvantage of the GHB and GBL models is that they represent an acute model of absence seizures rather than a chronic model of absence epilepsy, such as the genetic models $[14,17]$. However, the maturation of GBL-induced SWDs over time and spontaneous SWDs after the weekends in the present study indicated a fully synchronized paroxysmal activity, suggesting an augmentation in the cortico-thalamo-cortical network with repeated GBL administrations. The brief spontaneous bursts of bilaterally synchronous SWDs have been previously observed [28] following the acute administration of GBL as late as $72 \mathrm{~h}$. Indeed, the involvement of the cortico-thalamo-cortical circuitry has been well accepted in the pathophysiology of absence epilepsy based on the studies in the genetic and pharmacological absence epilepsy models [36-38]. This synchronized paroxysmal activity with the chronic administration of GBL suggests a change over time in the functional organization of absence seizure circuit that possibly occurs at the cellular and/or synaptic level in the thalamo-cortical circuitry. Taken together, the chronic systemic application of GBL may represent an epileptogenesis model for absence epilepsy itself, deserving particular attention in further studies.

Finally, we studied the interaction between kindling and a pharmacological model of absence in non-epileptic Wistar rats and encounter another clue for the mutual cross interaction between absence epilepsy and limbic epilepsy, without the existence of an abnormal genetic background.

Ethics Committee Approval: The experimental protocol was approved by the Marmara University Ethical Committee of animal research (date: 15.11.2011, number: 48.2011.mar).

Conflict of Interest: No conflict of interest was declared by the authors.

Financial Disclosure: This study was supported by Marmara University Research Council (BAPKO, SAG-D-300409-0116).
Authorship Contributions: Concept - MAC, OCS, FO; Design NC, MS, MAC, OCS, FO; Supervision - FO, EE, OCS; Fundings - FO, OCS; Materials - FO, OCS; Data collection and/or processing - NC, MS, OA, MGI; Analysis and/or interpretation - NC, MS, OA, MGI, FO; Literature review - NC, MS, FO; Writing - NC, MS, FO; Critical review - MAC, OCS, EE.

\section{REFERENCES}

1. Goddard GV, McIntyre DC, Leech CK. A permanent change in brain function resulting from daily electrical stimulation. Exp Neurol 1969;25:295-330. [CrossRef]

2. Coulter DA, McIntyre DC, Löscher W. Animal models of limbic epilepsies: what can they tell us? Brain Pathol 2002;12:240-56. [CrossRef]

3. McIntyre DC, Poulter MO, Gilby K. Kindling: some old and some new. Epilepsy Res 2002;50:79-92. [CrossRef]

4. Bertram EH. Temporal lobe epilepsy: where do the seizures really begin? Epilepsy Behav 2009;14 Suppl 1:32-7. [CrossRef]

5. Eşkazan E, Onat FY, Aker R, Oner G. Resistance to propagation of amygdaloid kindling seizures in rats with genetic absence epilepsy. Epilepsia 2002;43:1115-9. [CrossRef]

6. Onat FY, Eskazan E, Aker R. Experimental absence versus amygdaloid kindling. In: Corcoran ME, Moshe SL, editors. Kindling 6 Advances in Behavioral Biology. Springer; 2005. p. 37-47. [CrossRef]

7. Carçak N, Aker RG, Ozdemir O, Demiralp T, Onat FY. The relationship between age-related development of spike-and-wave discharges and the resistance to amygdaloid kindling in rats with genetic absence epilepsy. Neurobiol Dis 2008;32:355-63. [CrossRef]

8. Gurbanova AA, Aker RG, Sirvanci S, Demiralp T, Onat FY. Intraamygdaloid injection of kainic acid in rats with genetic absence epilepsy: the relationship of typical absence epilepsy and temporal lobe epilepsy. J Neurosci 2008;28:7828-36. [CrossRef]

9. Aker RG, Yananli HR, Gurbanova AA, Ozkaynakçi AE, Ateş N, van Luijtelaar G, et al. Amygdala kindling in the WAG/Rij rat model of absence epilepsy. Epilepsia 2006;47:33-40. [CrossRef]

10. Onat FY, Aker RG, Gurbanova AA, Ateş N, van Luijtelaar G. The effect of generalized absence seizures on the progression of kindling in the rat. Epilepsia 2007;48 Suppl 5:150-6. [CrossRef]

11. Akman O, Karson A, Aker RG, Ates N, Onat FY. Hippocampal kindling in rats with absence epilepsy resembles amygdaloid kindling. Epilepsy Res 2008;81:211-9. [CrossRef]

12. Akman O, Karson A, Aker RG, Ates N, Onat FY. Perirhinal cortical kindling in rats with genetic absence epilepsy. Neurosci Lett 2010;479:74-8. [CrossRef]

13. Snead OC $3^{\text {rd }}$. Gamma hydroxybutyrate in the monkey. I. Electroencephalographic, behavioral, and pharmacokinetic studies. Neurology 1978;28:636-42. [CrossRef]

14. Snead $\mathrm{OC} 3^{\text {rd }} \cdot \gamma$-Hydroxybutyric and absence seizure activity. In: Tunnicliff G, Cash CD, editors. Gamma-hydroxybutyrate: Molecular, functional and clinical aspects. London: Taylor and Francis; 2002, p. 132-49. [CrossRef]

15. Snead OC $3^{\text {rd }}$. Basic mechanisms of generalized absence seizures. Ann Neurol 1995;37:146-57. [CrossRef]

16. Wong CG, Gibson KM, Snead OC $3^{\text {rd }}$. From the street to the brain: neurobiology of the recreational drug gamma-hydroxybutyric acid. Trends Pharmacol Sci 2004;25:29-34. [CrossRef]

17. Venzi M, Di Giovanni G, Crunelli V. A critical evaluation of the gamma-hydroxybutyrate (GHB) model of absence seizures. CNS Neurosci 
Ther 2015;21:123-40. [CrossRef]

18. Snead OC $3^{\text {rd }}$. gamma-Hydroxybutyrate model of generalized absence seizures: further characterization and comparison with other absence models. Epilepsia 1988;29:361-8. [CrossRef]

19. Snead OC $3^{\text {rd }}$. The gamma-hydroxybutyrate model of absence seizures: correlation of regionalbrain levels of gamma-hydroxybutyric acid and gamma-butyrolactone with spikewave discharges. Neuropharmacology 1991;30:161-7. [CrossRef]

20. Paxinos G, Watson C. The rat brain in stereotaxic coordinates. $4^{\text {th }}$ ed. San Diego: Academic Press; 1998.

21. Lettieri J, Fung HL. Improved pharmacological activity via pro-drug modification: comparative pharmacokinetics of sodium gamma-hydroxybutyrate and gamma-butyrolactone. Res Commun Chem Pathol Pharmacol 1978;22:107-18.

22. Racine RJ. Modification of seizure activity by electrical stimulation. II. Motor seizure. Electroencephalogr Clin Neurophysiol 1972;32:28194. [CrossRef]

23. Nanobashvili Z, Chachua T, Nanobashvili A, Bilanishvili I, Lindvall O, Kokaia Z. Suppression of limbic motor seizures by electrical stimulation in thalamic reticularnucleus. Exp Neurol 2003;181:224-30.

24. Glasscock E, Qian J, Yoo JW, Noebels JL. Masking epilepsy by combining two epilepsy genes. Nat Neurosci 2007;10:1554-8. [CrossRef]

25. Hanaya R, Koning E, Ferrandon A, Nehlig A. The role of the inherited genetic background on the consequences of lithium-pilocarpine status epilepticus: study in Genetic Absence Epilepsy Rats from Strasbourg and Wistar audiogenic rats. Neurobiol Dis 2008;31:451-8. [CrossRef]

26. Bowyer JF, Albertson TE, Winters WD. Cortical kindled seizures: modification by excitant and depressant drugs. Epilepsia 1983;24:35667. [CrossRef]

27. Bowyer JF, Winters WD. The effects of various anesthetics on amygdaloid kindled seizures. Neuropharmacology 1981;20:199-209. [CrossRef]

28. Hu RQ, Cortez MA, Man HY, Roder J, Jia Z, Wang Y'T, et al. Gammahydroxybutyric acid-induced absence seizures in GluR2 null mutant mice. Brain Res 2001;897:27-35. [CrossRef]
29. Hu RQ, Cortez MA, Man HY, Wang YT, Snead OC $3^{\text {rd }}$. Alteration of GLUR2 expression in the rat brain following absence seizures induced by gamma-hydroxybutyric acid. Epilepsy Res 2001;44:41-51. [CrossRef]

30. Ryu MJ, Kim D, Kang UB, Kim J, Shin HS, Lee C, et al. Proteomic analysis of gamma-butyrolactone-treated mouse thalamus reveals dysregulated proteins upon absence seizure. J Neurochem 2007;102:64656. [CrossRef]

31. Scott BW, Chan KF, Wong G, Ahmed M, Chieverton L, Liu RR, et al. Cytogenesis in the adult rat dentate gyrus is increased following kindled seizures but is unaltered in pharmacological models of absence seizures. Epilepsy Behav 2010;18:179-85. [CrossRef]

32. Depaulis A, Bourguignon JJ, Marescaux C, Vergnes M, Schmitt M, Micheletti $G$, et al. Effects of gamma-hydroxybutyrate and gammabutyrolactone derivates on spontaneous generalized non-convulsive seizures in the rat. Neuropharmacology 1988;27:683-9. [CrossRef]

33. Depaulis A, Snead OC $3^{\text {rd }}$, Marescaux C, Vergnes M. Suppressive effects of intranigral injection of muscimol in three models of generalized non-convulsive epilepsy induced by chemical agents. Brain Res 1989;498:64-72. [CrossRef]

34. Akman O, Demiralp T, Ates N, Onat FY. Electroencephalographic differences between WAG/Rij and GAERS rat models of absence epilepsy. Epilepsy Res 2010;89:185-93. [CrossRef]

35. Drinkenburg WH, van Luijtelaar EL, van Schaijk WJ, Coenen AM. Aberrant transients in the EEG of epileptic rats: a spectral analytical approach. Physiol Behav 1993;54:779-83. [CrossRef]

36. Coenen AM, Van Luijtelaar EL. Genetic animal models for absence epilepsy: a review of the WAG/Rij strain of rats. Behav Genet 2003;33:635-55. [CrossRef]

37. Velazquez JL, Huo JZ, Dominguez LG, Leshchenko Y, Snead OC $3^{\text {rd }}$. Typical versus atypical absence seizures: network mechanisms of the spread of paroxysms. Epilepsia 2007;48:1585-93. [CrossRef]

38. Cope DW, Di Giovanni G, Fyson SJ, Orbán G, Errington AC, Lorincz ML, et al. Enhanced tonic GABAA inhibition in typical absence epilepsy. Nat Med 2009;15:1392-8. [CrossRef] 